\title{
The Protection and Inheritance of Liaozhai Folk Songs
}

\author{
Zhihong Zhang \\ Musical College Qingdao University Shandong Province China
}

13156381105@163.com

KeyWords: Liaozhai Folk Songs; Protection; Inheritance; Tunes

\begin{abstract}
Liaozhai folk songs are easy-to-read dialect adapted from many stories in Strange Tales from a Chinese Studio by Pu Songling, a great litterateur and king of the short story in the late Ming and early Qing Dynasties, which matched with the popular folk songs in the Zichuan area in the Ming and Qing Dynasties, and are a large telling and singing story. After three hundred years of the vicissitudes of life, Liaozhai folk songs became decadent from prosperity. Since the 1950s and 1960s, musicians and government departments have not stopped rescuing and protecting them, including the arrangement of tunes, the creation of new plays and the cultivation of folk songs talents. Under the background of social transformation, how to get the better inheritance and development of Liaozhai folk songs through open and inclusive attitude is the common thinking of music workers.
\end{abstract}

\section{Introduction}

Liaozhai folk songs are an ancient music, which appeared more than 300 years ago, and created by Pu Songling, a great litterateur and king of the short story in the early Qing Dynasty. Strange Tales from a Chinese Studio written in classical Chinese, and ordinary people cannot understand it, $\mathrm{Pu}$ Songling (1640-1715) adapted many of these stories from Liaozhai by easy-to-read dialect, which matched with the popular folk songs in the Zichuan area in the Ming and Qing Dynasties, creating a large telling and singing story, which called Liaozhai folk songs. According to the Tombstone of Mr. Pu Liuquan written by Mr.Zhang Yuan in 1752, Pu Songling has made a total of fourteen works of Liaozhai folk songs. They are Gu Fu Song, Ci Bei Song, Fan Yan Yang, Rang Du Zhou, Mo Nan Song, Han Sen Song, Zeng Bu Xing Yun Song, Penglai Banquet, Jun Ye Cha, Kuai Song, Chou Jun Ba, Qiang Tou Record and Qiong Han Ci. If you see Rich Fairy and Mo Nan Song as respective one, then there are 15 works for Liaozhai folk songs.

\section{The Spectacular Event and Reason of Liaozhai Folk Songs.}

Liaozhai folk songs have been widely sung by the public since the Qing Dynasty. The early performance is used to entertain the masses themselves. When people have finished their folk activities on fifteenth day of the first month of Lunar Year, the team composed by a group of villagers made up in Pujia county would sing Qiang Tou Record, Gu Fu Song and so on; another form of Liaozhai folk songs is "one sings while the crowd listen". In the prosperous belt of Zichuan, Zhoucun and Boshan, there are always such occasion that one is chanting and singing folk songs surrounded by the crowed, and people called it "chanting folk songs", which means that there are already professional or semi-professional artists specializing in the singing of the songs. With its unique charm, Liaozhai folk songs have influenced the development of other sister arts, the Five-tone play, Liuzi drama, Sichuan opera, Peking Opera, Qinqiang opera, Hebei Bangzi and many other kinds of plays are adapted from the stories of Liaozhai.

Liaozhai folk songs produced and circulated quickly, first of all, it is the Times that endows it the specific social-economic and cultural soil to develop: at that time, the folk songs of Ming dynasty in Zichuan were popular and that of Qing dynasty had a greater development, so it can be said that Zichuan was one of the important areas of Ming and Qing Dynasties folk songs. The 15 folk songs 
of Pu Songling' s works all came from the popular tunes of that time, such as Juggling Children, Silver Wire, Folding Bridge, Ya Ya You, Broken Riving Jade, Falling Money, Dao Ban Jiang, Fang Si Niang, Zao Luo Pao and Huang Ying Er. In addition, Liaozhai folk songs are an art that is easy to be accepted by the general public: using vernacular and dialect to speak the story, it sounds obvious and friendly; it is widely used for slang, proverbs and Xiehouyu, and has a humorous and lively style; the main part of folk songs is to write about the daily life of the peasant people, such as the problem of old-age care, the relationship between husband and wife, the relationship between mother-in-law and daughter-in-law, etc; which are the hot spots of concern for the people and are apt to resonate and produce social effects.

\section{The Present Situation and Rescue Work of Liaozhai Folk Songs in Modern Times}

After three hundred years of the vicissitudes of life, the popular singing of folk songs of the past is long gone. Why? Liaozhai folk songs went through a long time from spread to disappearance. "It is from popular to lost, and the partial loss is the essence, which may have quite complicated social reasons." ${ }^{[1 p] 790}$ It is said that some people can sing the whole folk songs around 1897. In 1937, after the "July 7th" incident, Japanese invaded China and people were not living in peace, and the singing activities of folk songs were very rare. There are only ten of more than original 50tune names, less than a fifth of the total number of that of folk songs.

Before 1950s to Cultural Revolution, music workers had taken a series of rescue efforts for the Liaozhai folk songs: the cultural workers, represented by Mr. Mou Renjun, first visited the blind artist liu Dunzi near the village of pu jiazhuang and Han Bingxiang of Shili village, collected, excavated, record and arranged Liaozhai folk songs; Mr. Wang Chuankun also began to pay attention to the exploring and rescue work; at the beginning of 1960s, Zibo gathered the literary backbone and carried out the census of folk music, compiled Zibo Folk Songs Selection, which included 13 tunes in Liaozhai folk songs; in 1963, China Music Research Institute Mr. Wu Zhao went to Zichuan to collect folk songs, such as listening to Pu Renrun's singing of folk tunes in Pu Jiazhuang, recording a rap song Shua Haier song by blind artists, and writing a book Pu Songling folk songs; at the same time, Hou Yushuang, Yan Naiying joined the Zibo literature and art team to participate in the whole province's folk songs, which attracted the attention of experts and scholars. The delegation to the provincial conference also toured the city and was welcomed by all levels of leadership and the people. During the period of the "Cultural Revolution" and for the next almost 20 years, there was no one to talk about folk songs.

\section{Circulation and Protection of Liaozhai Folk Songs in Contemporary Time.}

A series of achievements have been made in the inheritance and protection of Liaozhai folk songs in contemporary time: In 2006, they were recorded into the first list of National Intangible Cultural Heritage. In May 2008, music workers Chen Qian, Yang Daokun, Wang Shizhong and Zhang Pujun as inheritor of Liaozhai folk songs, invited more than 20 fruitful scholars to host the "seminar on Liaozhai folk songs". In July 2008, Liaozhai art troupe was established in Zibo district in which new repertories of Going to Husband's Family as bride Together with Grandma", "the Young Female Dean", " Beg for Scolding", "Wang Liulang", "Sisters Who Are Easy to Get Married", "Environmental Protection Guard" and so on were made and performed. It can be said that the development of Liaozhai folk songs in contemporary time are not confined to old form of rap, but consciously explore new form on the stage. The adaptation of Liaozhai folk songs has formed "Liaozhai folk songs opera", and in 2016, it has declared a new Chinese opera, which has been adapted into a total of 12 plays. At present, the Liaozhai art troupe has become a demonstration base for the revitalization of local operas in Shandong province. To make them inherited further, Liaozhai art troupe and Zichuan district experimental primary school jointly set up a children's art troupe who holds children's training classes and regard them as school-based curriculum.

The protection and inheritance of Liaozhai folk songs have achieved a series of achievements not 
only in the practice of stage performance, but also in the theoretical field of the study of Liaozhai folk songs: In 2013, the government work report from the second meeting of the sixteenth session of the people's congress in Zichuan district of Zibo, pointed out clearly the need to strengthen the protection of intangible cultural heritage such as Liaozhai folk songs. Some specialized agencies like $\mathrm{Pu}$ Songling research institute, Banyang culture research center were established and four large-scale seminars on the theory of Liaozhai folk songs were hold. "Study on Liaozhai folk songs" column was opened on journals $\mathrm{Pu}$ Songling Research and Banyang Culture, which discusses and demonstrates comprehensively the theory of Liaozhai folk songs, and provides some suggestions for the development and inheritance of Liaozhai folk songs. Music scholars Chen Yuchen as representative made great achievements in the study of Liaozhai folk songs: they published a series of papers like Artistic Features of Liaozhai folk songs, The Origin of Liaozhai folk songs, Walk toward < Ya Ya You>, Looking for <Fang Si Niang> , < Gu Fu Song > Tune Name Partition, From Bianwen to Folk Songs, Folk Origin Theory, < Fast Song > Creative and Brief Ideas and monographs like The General Theory of Liaozhai Folk Songs and Liaozhai Folk Songs. In addition, Chen Qian and Yang Daokun collected and sorted out 12 kinds of tune names and 19 kinds of songs on the edge of distinction, and compiled A talk on the Collection of Liaozhai Folk Songs, printed 1200 copies and distributed them to the Zichuan culture department, villages and towns cultural stations, which greatly promote the communication of Liaozhai folk songs.

More importantly, the government authorities are paying more and more attention to the protection of Liaozhai folk songs. The government work report from the second meeting of the sixteenth session of the people's congress in Zichuan district of Zibo, points out that we should strengthen the protection of intangible cultural heritage like Liaozhai folk songs. In early 2017, Shandong Art Research Institute officially launched a protection plan for Liaozhai folk songs, before which they have acquainted minutely the historical origin and artistic features, communication and the troupe's composition and performance status, and collected a large number of texts, audio and video data through field research and colloquium in Zichuan.

\section{There is Still a Long Way to go for the Protection and Inheritance of Liaozhai.}

Although the protection and inheritance of Liaozhai folk songs have made great achievements in modern times, the era of it as mainstream entertainment is gone. From the perspective of art itself, no art school in the history can be active and prosperous forever, whether drama, folk arts, music or art, all of them experience flourishing and depression, which is the law of nature in the development of art and things. From the perspective of external environment, there are diversified entertainment forms in contemporary time. The appearance of television and the rapid development of the Internet make people enjoy all kinds of programmer staying home in recent years, especially the wide application of smart phones makes people can surf the Internet anytime and anywhere, play games, watch movies and look through all kinds of information and so on. Opera and stage theatre are no longer the main forms of entertainment. In addition, the aesthetic concept of people in contemporary society has changed a lot. The mass consumer culture, which is characterized with entertainment, pursuit of fashion and convenience, has become the mainstream. Traditional classical culture, taking drama as representative, is affected seriously. We can imagine that it is very difficult for Liaozhai folk songs to be inherited and developed in such an environment.

\subsection{The Exploring and Collating of "Discarding the False and Retaining the True".}

Liaozhai folk songs are different from the traditional opera, which are the "living fossil" of Ming and Qing dynasties. The Ming and Qing Dynasties folk songs play a very important role in the history of Chinese music. They are the direct inheritance and development of song and yuan song tunes, which are rich in melody, complex in content and widely circulated. According to folk songs ditties in Ming and Qing Dynasties arranged by Yang Liuyin, there are 31 works in Ming dynasty, such as Suo Nan Zhi, Shan Po goat, Da Zao Gan and so on; there are 280works in Qing dynasty, such as Nao Wu Geng, Ji Sheng Cao, Yin Niu Si, Jian Ding Hua, Wang Da Niang, Man Jiang Hong, 
Xian Hua Diao (Jasmine Flower) and so on. In fact, there are more folk songs than these. At that time, the selection of Liaozhai folk songs were over 50 kinds, most of which have been lost, leaving only more than 10 kinds at present, which can be said to be a huge regret. In this case, the protection and rescue work of Liaozhai folk songs are not only to retain the above tunes, but there is problem how to distinguish the authenticity of the existing tunes. Because the spread way of "oral transmission and inner understanding" gone through 300 years which is very easy to distort the original tunes, even beyond recognition. For example, using the same tune to sing Fang Si Niang, Ku Huang Tian and Han Tou Lang, what a strange tune it is. It cannot be understood that the tunes used in Die Luo Jin Qian and also in Han Tou Lang. There are some people who self made tunes to imitate folk songs. For example, Ya Ya You and other two tunes are self made by contemporary people, in which Fen Huang Lian tune was used in Ya Ya You, and Huang Ying Er, Die Luo Jin Qian are created in accordance with tunes of the other small folk songs that people know before. How to inherit folk songs and what degree will it inherit in this situation? Well, where are certified folk songs? Who knows where the other more than 40 songs are? In this regard, more experts like Chen Yuchen are needed to establish "advanced art scientific and research project".

\subsection{The Talents Cultivation and Innovation of Liaozhai Folk Songs}

"Strong youths lead to a strong China", similarly, only starting with the doll in education, then can make the inheritance of Liaozhai folk songs go further. At present, among more than 50 people in Liaozhai art troupe in the Zibo district, there are few people are under the age of 50, with a serious aging problem and lacking of professional skills. Therefore, Liaozhai art troupe made great efforts: to start a training class for children, to make Liaozhai folk songs as an elementary school curriculum, and to conduct regular training for music teachers in all urban primary schools and central primary schools in township. Promoting Liaozhai folk songs lessons in the whole areas, with the aid of music teacher's professional knowledge and skills, continuously develop Liaozhai folk songs as young team, apply to the district government to establish related posts of Liaozhai folk songs in Zichuan cultural center, strive for compilation for Liaozhai folk songs' workers, especially those youth drama talents would like to contribute to folk songs.

Facing national treasure of Liaozhai folk songs, singing is the best inheritance. Otherwise Liaozhai folk songs like a broken winged bird became the desk literature. But what can we sing? The author believes that we can adopt diversified thinking and absorb the elements of contemporary music. Liaozhai folk songs created by Pu Songling also used the tunes popular in that time. The drama has been changing since its birth, the formation of the opera and each development are the result of the fusion of many performances, and it can be said that it is the important law in the development of drama. Therefore, in line with the principle of great openness and inclusiveness, as long as it is conducive to the development of Liaozhai folk songs, all of them can be used. Fashionable network language, pleasant pop songs, witty funny jokes, affectionately spoken, appreciating dancing figure, difficult acrobatics and performances that closed to life can be integrated into the performance of Liaozhai folk songs. The creation of play is not only from Strange Tales of Chinese Studios, but also in accordance with contemporary aesthetic appeal and closed to real life. These works can not only be performed on the stage, but also sung by ordinary people. If some of them have become classic film and television episodes, people may have forgotten the plot of the movie and TV series, but the episodes in them have been sung by generations. This job is easier to be said than to be done. It requires that the creators with a considerable artistic attainment composite work which are in accordance with the trend of the times and are characterized with Liaozhai. Meanwhile, in the singing of Liaozhai folk songs, we should also boldly learn singing methods from Bel canto and Popular.

Liaozhai folk songs require not only innovation but also inheritance. Of course, innovation is also a part of inheritance. On the other hand, we should try to keep Liaozhai folk songs original. The emphasis is on the performance of the tunes of Liaozhai folk songs, including the line, the cavity, the bite, the performance and so on. 
Liaozhai folk songs are facing an unprecedented development crisis like many other intangible cultural heritages, but as a true national art, as the crystallization of national culture and wisdom, the extremely common Liaozhai folk songs deeply rooted in folk people's minds and folk fertile soil. Zibo people are proud of Liaozhai folk songs which are the cultural card of Zibo and feelings that are difficult to give up. The rescue, protection and inheritance of Liaozhai folk songs have achieved considerable achievements through the selfless dedication of many old artists. How to make Liaozhai folk songs more open and inclusive, and help it go farther under the background of social transformation, which require the joint thinking of whole society, especially the relevant government departments and music workers.

\section{References}

[1] Yang Liuyin. Chinese Ancient Musical History Draft(M) Beijing People's Music Press. P79

[2] Zhou Yanxiang. An Unignorable Inheritor of Liaozhai Folk Songs, the Composer and Expert on the Music, Professor Chen Yuchen's Teaching Experience.The Public Daily. 2014.4.24

[3] Sun Aiju. Liaozhai Folk Songs: A Century of Heritage and Appreciation. Chinese Information (J) 2015 (10)

[4] Bright Pearl Put Light in Night. Zibo Municipal People’s Government Website.

[5] Chen Yuchen. The General Theory Liaozhai Folk Songs . Pu Songling Research (J) 1997 (4)

[6] Chen Yuchen. Walk toward Ya Ya You. Pu Songling Research (J) 1997 (4) 